Just, Thomas; Riedel, Florian; Husar, Peter:

\title{
A low-cost system for recording auditory brainstem responses
}

Zuerst erschienen in: Biomedical Engineering = Biomedizinische Technik. - Berlin [u.a.] : de Gruyter. - 57 (2012), Suppl. 1, Track-F, p. 673.

Erstveröffentlichung: $\quad$ 2012-08-30

ISSN (online): $\quad$ 1862-278X

ISSN (print): 0013-5585

DOI: $\quad 10.1515 / \mathrm{bmt}-2012-4539$

[Zuletzt gesehen: 2019-08-12]

„Im Rahmen der hochschulweiten Open-Access-Strategie für die Zweitveröffentlichung identifiziert durch die Universitätsbibliothek IImenau."

"Within the academic Open Access Strategy identified for deposition by Ilmenau University Library."

„Dieser Beitrag ist mit Zustimmung des Rechteinhabers aufgrund einer (DFGgeförderten) Allianz- bzw. Nationallizenz frei zugänglich."

"This publication is with permission of the rights owner freely accessible due to an Alliance licence and a national licence (funded by the DFG, German

Research Foundation) respectively." 


\title{
A Low-cost System for Recording Auditory Brainstem Responses
}

\author{
T. Just ${ }^{1}$, F. Riedel ${ }^{2}$ and P. Husar ${ }^{3}$ \\ Institute of Biomedical Engineering and Informatics, Ilmenau University of Technology, 98693 Ilmenau, Germany; \\ phone: +49 3677 69-2860; fax: +49 3677 69-1311; \\ e-mail: ${ }^{1}$ thomas.just@tu-ilmenau.de, ${ }^{2}$ florian.riedel@tu-ilmenau.de, ${ }^{3}$ peter.husar@tu-ilmenau.de
}

\section{Introduction}

Auditory brainstem responses (ABR) are of high importance for the detecting and monitoring neural damage of the auditory nerve and the auditory brainstem. ABRs are a promising approach for hearing screening and objective assessment of hearing quality. Furthermore, it can be used for objective validation of the function of cochlear implants. [1]

For measurement and data acquisition of ABRs two types of systems exists. While two-channel systems (without rawdata storage capability) limit online and subsequent data analysis, the multichannel systems are very expensive and thus are not common.

We propose a method for simultaneous stimulation and data acquisition of ABRs using a simple and low-cost amplifier in combination with a multichannel USB soundcard, $192 \mathrm{kHz}$ and a resolution of 24 bit. These parameters are excellent for recording EEG with high temporal and binary resolution.

\section{Methods}

A commercial studio soundcard (RME Fireface UC, Heimhausen, Germany) was used for both providing the acoustic stimulus and recording the EEG signals. An acoustic click signal was provided via ear headphones. The stimulation was repeated 1,000 times at the left ear. For recording of EEG signals, a custom amplifier (hardware gain $=10,000$ ) was connected to. The electrodes were placed at M1 and M2 as well as Cz. The Cz signal was referenced to M1 and the patient ground was placed at M2 [2]. For controlling the soundcard a self-developed software was used.

\section{Results}

Figure 1 shows the ABR with main components I to VI. The results show that a soundcard is able to present an auditory stimulus and record EEG signals with a sample rate of $192 \mathrm{kHz}$.

\section{Conclusion}

We are able to measure biological signals with a low-cost system. In future works the multichannel acquisition will be used for applying spatial filters and calculate the components of the ABR to improve the diagnostics of neural damages.
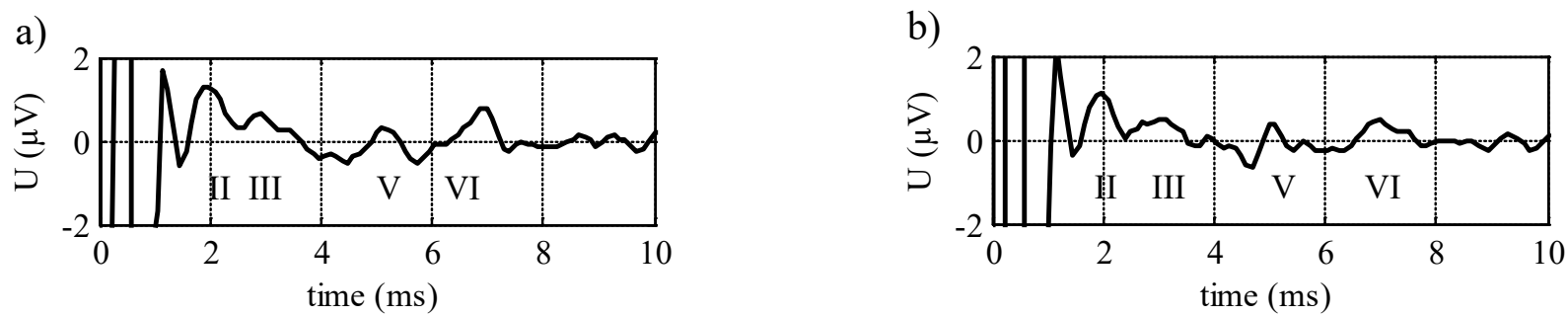

Figure 1:Recorded ABR using a studio soundcard, averaged over 1000 trials; a) ABR of subject 1; b) ABR of subject 2

\section{References}

[1] J. Jörg, H. Hielscher, Evozierte Potentiale in Klinik und Praxis, Berlin Heidelberg: Springer-Verlag, 1997.

[2] J. W. Hall, New handbook of auditory evoked responses, Pearson, 2007. 